\title{
A SURVEY OF PATIENTS USING SPECTACLE MAGNIFIERS*
}

\author{
BY \\ G. S. WILLETTS \\ Birmingham and Midland Eye Hospital
}

\begin{abstract}
SiNCE November, 1957, Igard Hyperocular Spectacle Magnifiers have been prescribed at this hospital for unselected patients with permanent low visual acuity, who achieved a satisfactory result when tested with these lenses. The testing set consists of a single-celled trial frame fitted with adjustable distancing posts (to act as stops against which the reading matter is held), an occluder, and the three lenses glazed to $40-\mathrm{mm}$. trial rims. The lenses are plastic, aspherical, biconvex, solid lenticulars of magnifications $4 \times(+16 \mathrm{D})$, $6 \times(+24 \mathrm{D})$, and $8 \times(+32 \mathrm{D})$. In practice it was found possible to dispense with the distancing posts, even though the reading matter had to be held in the focal plane of the lens, giving a short and critical working distance.

Some of the difficulties arising in the use and design of spectacle magnifiers have been reviewed by Lederer (1954), and a summary of low visual aids, including spectacle magnifiers, currently available has been compiled by Williamson (1958). In February, 1959, it was thought that sufficient of the lenses had been prescribed for an assessment of their value to the patients to be made. About seventy patients were therefore asked to attend with their hyperocular glasses, but only 44 presented themselves for examination.
\end{abstract}

\section{RESULTS}

February, 1959.-The patient's visual acuity with the hyperocular lenses was compared with that recorded when the lenses were prescribed, and the patient's opinion of the lenses was noted.

Sex and Age.-There were 24 males and twenty females, and their ages ranged from 16 to 86 years (average 63).

Lesions.-The principal conditions leading to defective vision in these patients are listed in the Table (overleaf).

It was discovered that two of the patients had not in fact had the spectacle magnifiers prescribed for them but had alternative reading low visual aids, and these two cases are excluded, leaving $\mathbf{4 2}$ for the analysis.

* Received for publication March 3, 1960. 
TABLE

OCULAR LESIONS IN 44 PATIENTS USING HYPEROCULAR SPECTACLE MAGNIFIERS

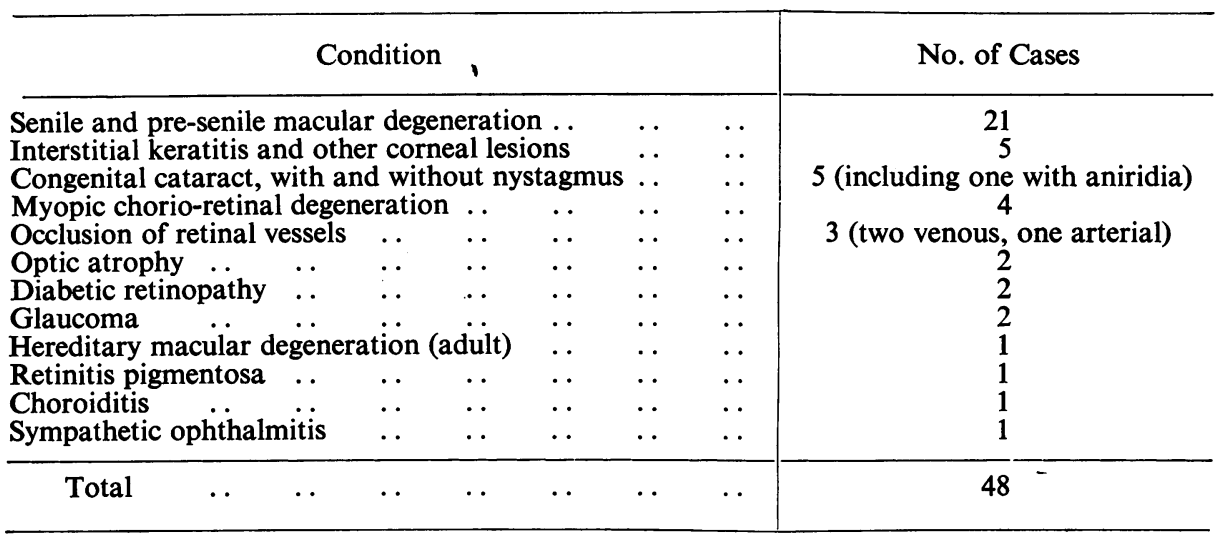

Note: Four patients are included twice in these figures since they suffered from two contributory conditions. Lens opacities of varying degrees were present in many of the cases.

Visual Acuity.-All the patients in this survey had achieved N5 when the lenses were prescribed, except three, two who had read N8 and one who had read N6. These three patients all showed a deterioration in reading visual acuity with the hyperoculars, although one claimed that they were still satisfactory and another had spent the previous 3 months in hospital without using the glasses.

Of the remaining 39 patients, 24 (61 per cent.) could still read N5, a further ten ( 26 per cent.) could read N8 or better, and the rest ( 13 per cent.) could read only less than N8. The five patients in the last group, showing the greatest deterioration in reading visual acuity, all had potentially progressive ocular lesions.

Subjective Report.-Of the 42 patients using hyperoculars, 24 (57 per cent.) found them satisfactory, seven (17 per cent.) found them of limited use (e.g. for newspaper headlines), and eleven ( 26 per cent.) found them useless.

Owing to the limited response to the request for patients to attend for this survey, several of those who are included had been using the hyperoculars for a relatively short time (average 9 months). It was therefore decided to re-examine the same patients after a further 6 months and a second survey was carried out in September and October, 1959.

September-October, 1959. - Of the 44 patients seen in February, 31 (70 per cent.) attended for re-examination, three ( 7 per cent.) were notified as deceased, five (11 per cent.) refused to attend (two because of illness or work, and three because they thought their vision now so poor that attendance would be useless), and five (11 per cent.) did not reply. 
The 31 patients re-examined included the two not using hyperocular lenses, and one other patient had had a cataract extraction since the first survey and was fortunately now able to read N5 with a normal aphakic reading correction. These three patients are excluded from the analysis of the results. Another patient had found the hyperocular lens useless in February, owing to the development of an absolute central scotoma in the eye for which the lens had been prescribed, but was now able to read N5 with the lens transposed to the other eye; this patient is included in the analysis, making a total of 28 . Of these patients, 23 (82 per cent.) had maintained the same standard for the 6 months.

A further small group of patients using hyperoculars was asked to attend for the first time, and ten presented themselves for examination, but one was found to have had the lenses incorrectly prescribed and so is excluded from the final analysis.

This makes a total of 41 patients examined in September and October, 1959, of whom 37 were using hyperoculars.

Visual Acuity.-Of these 37 all but two had achieved N5 originally. 24 ( 65 per cent.) of the 37 could still read N6 or better, a further eight ( 22 per cent.) could read N8, and the remaining five (13 per cent.) could read only $\mathrm{N} 10$ or less (these included the two patients able to read only N8 when the lenses were prescribed).

Subjective Report.-Of the 37 patients using hyperoculars, 25 (60 per cent.) found them satisfactory, nine ( 24 per cent.) found them of limited use, and six (16 per cent.) found them useless, although some of this last group admitted to being able to read by other means, such as a hand magnifier.

\section{Conclusions}

A bias towards patients finding the hyperoculars satisfactory may have unavoidably affected the results of this survey owing to the limited response by the patients asked to attend. That 60 per cent. of the patients seen should find the lenses useful is felt to be encouraging. The few younger patients for whom the lenses had been prescribed almost universally found them satisfactory. More of the older patients with low visual acuity suffered from multiple ocular pathology with a greater tendency to progressive visual deterioration. This, combined with the more limited adaptability of the elderly, tended to restrict the value of these lenses for this large group of patients. A further limiting factor in the value of such lenses to the elderly is the high mortality rate, 7 per cent. being known to have died in a period of only 6 months.

One or two of the younger patients were enabled to learn to read visually for the first time with these lenses. 
A high degree of reading visual acuity (e.g. N5 read with ease and understanding of the context) at the time the refraction is performed should be aimed at before the lenses are prescribed. Almost all the patients in this survey who did not achieve N5 when the lenses were prescribed showed deterioration in reading ability and found the lenses to be unsatisfactory.

\section{Summary}

The results of a survey of patients using hyperocular spectacle magnifiers carried out in February, 1959, are described. Of 42 patients using the lenses, 24 could still read N5 but eight could read only less than N8. Subjectively, 24 found them satisfactory and eleven found them useless. 31 of these patients were re-examined after a further 6 months, when 28 were still using hyperoculars and $23 \mathrm{had}$ maintained their reading visual acuity. A further nine patients with hyperoculars were reviewed for the first time during this second survey. 24 of this total of 37 patients using hyperoculars seen in the course of the second survey could still read N6 or better but five read only N10 or less. Subjectively, 22 of the 37 patients found the lenses satisfactory and six found them useless.

It is pointed out that the lenses were found to be more useful by the younger than by the elderly patients. A high standard of reading acuity with the lenses is advised before they are prescribed.

I am indebted to the Consultant Staff of the Birmingham and Midland Eye Hospital for permission to examine their patients and to Dr. D. R. Campbell for her encouragement and advice in the preparation of this paper. My thanks are due also to Mr. B. Macnamara, senior refractionist, and to the secretarial staff of the hospital for their assistance.

\section{REFERENCES}

LEDERER, J. (1954). Nature (Lond.), 174, 977.

Williamson, D. G. (1958). Optician, 136, 134. 